\title{
Polycyclic Aromatic Hydrocarbons (PAHs) in Fired Clay Bricks Incorporating Cigarette Butts
}

\author{
Halenur Kurmus ${ }^{1, *}$, Abbas Mohajerani ${ }^{1}\left(\mathbb{D}\right.$ and Stephen Grist ${ }^{2}$ \\ 1 School of Engineering, RMIT University, Melbourne, VIC 3000, Australia; abbas.mohajerani@rmit.edu.au \\ 2 School of Applied Sciences, RMIT University, Melbourne, VIC 3000, Australia; stephen.grist@rmit.edu.au \\ * Correspondence: halenur.kurmus@student.rmit.edu.au
}

Citation: Kurmus, H.; Mohajerani, A.; Grist, S. Polycyclic Aromatic Hydrocarbons (PAHs) in Fired Clay Bricks Incorporating Cigarette Butts. Materials 2021, 14, 2032. https:// doi.org/10.3390/ma14082032

Academic Editor: Antonio Caggiano

Received: 22 March 2021

Accepted: 15 April 2021

Published: 18 April 2021

Publisher's Note: MDPI stays neutral with regard to jurisdictional claims in published maps and institutional affiliations.

Copyright: (C) 2021 by the authors Licensee MDPI, Basel, Switzerland. This article is an open access article distributed under the terms and conditions of the Creative Commons Attribution (CC BY) license (https:// creativecommons.org/licenses/by/ $4.0 /)$.

\begin{abstract}
Cigarette butts (CBs) are the most common littered waste in the world and may contain polycyclic aromatic hydrocarbons (PAHs) from the incomplete combustion of tobacco during burning. Therefore, to investigate the potential PAH residual remaining in fired clay bricks (FCBs) incorporating $\mathrm{CBs}$ and examine the environmental impact of utilizing toxic waste in the production of FCBs, a comprehensive PAH extraction analysis was conducted. The Soxhlet extraction method was utilized to conduct a qualitative and quantitative analysis of sixteen toxic Environmental Protection Authority (EPA) Polycyclic Aromatic Hydrocarbons (PAHs) in FCB samples incorporating CBs using gas chromatography-mass spectrometry (GC-MS). The concentrations of the mean total $(\Sigma)$ PAHs for FCBs incorporating $0 \%, 0.5 \%, 1 \%, 1.5 \%$, and $2 \%$ CBs by weight (wt) were found to be 0.183 , $0.180,0.242,0.234$, and $0.463 \mu \mathrm{g} / \mathrm{mL}$. As expected, PAHs with higher water solubility and volatility, naphthalene, fluorene, anthracene, pyrene, fluoranthene, and chrysene were found at higher concentrations compared to lipophilic PAHs. The $\Sigma \mathrm{PAH}$ concentrations for all five FCB-CB mixes were well below the EPA Victoria solid waste hazard categorization threshold for industrial waste. Moreover, the samples were studied for their carbon content using the carbon, hydrogen, nitrogen, and sulfur (CHNS) analyzer and thermogravimetric analysis (TGA). The results confirm an almost $100 \%$ combustion process of CBs during the firing process. A content less than $0.3 \%$ suggests that all carbon within the FCB-CB mixture relatively disappeared during the firing process up to $1050{ }^{\circ} \mathrm{C}$. However, further research regarding the emission of volatile organic compounds (VOCs) during the production of FCBs incorporating CBs should be conducted.
\end{abstract}

Keywords: polycyclic aromatic hydrocarbons (PAHs); cigarette butts; recycling; fired clay bricks; environmental sustainability

\section{Introduction}

Globally, over 5.4 trillion cigarettes are produced, and approximately one-third of cigarette butts (CBs) are littered into the nearby environment [1-3]. In Australia, CBs are the most common littered waste under the miscellaneous category, representing 91.5\% [3,4]. When littered, CBs persist in the environment for up to 10 years due to the composition of the filter. The filter of a CB is made from cellulose acetate, and, although cellulose is biodegradable, the acetate content prevents the cellulose from biological decomposition in an open environment [3,5]. A study conducted in a controlled laboratory condition found that it took up to 720 days for a CB to lose $30 \%$ to $35 \%$ of its total weight while decomposing [6].

In cigarette smoke, it is possible to classify more than 4000 chemical components generated during burning or distilled from the tobacco [3]. Essentially, the role of the filter of the $\mathrm{CB}$ is to trap and absorb the particulate smoke components, consisting of more than 3500 non-volatile and semi-volatile chemical compounds. The main toxic compounds include polycyclic aromatic hydrocarbons (PAHs), nicotine, metals, catechols, carbonyls, alcohols, nicotine alkaloids, and compounds specific to Solanaceae $[7,8]$. Therefore, when 
CBs are improperly disposed of, they pose a toxicant risk to the global environment and urban and aquatic life, whereby harmful chemicals are leached $[9,10]$. The leachate of the toxic compounds may eventually contaminate surface water and groundwater [11,12], and ultimately bioaccumulate in the human food chain and wildlife $[13,14]$.

Based on several years of research, Mohajerani et al. [15] proposed that the CB conundrum can potentially be eliminated by incorporating $1 \%$ CBs into $2.5 \%$ of the world's total FCB production. Various mechanical and physical tests were conducted to determine the practicality and competency of incorporating toxic waste in the production of FCBs, and the results were promising [16-20]. The tests included compressive strength, density, water absorption, initial rate of absorption, efflorescence, shrinkage, energy savings, thermal conductivity, and gas emissions. The research continued with the implementation phase of recycling CBs in FCBs, whereby several sterilization methods and odor elimination techniques were reviewed, CB collection systems were explored, and an implementation procedure was proposed on an industrial scale [21]. However, an environmental issue that may evolve through the addition of CBs in the construction of FCBs is the potential leachate of heavy metals and toxic chemicals during the use and disposal of the material. In 2020, Kurmus and Mohajerani [22] conducted a comprehensive leachate study of heavy metals from FCBs incorporating various percentages of CBs. The modified FCBs were found to be below the regulatory threshold limits and categorized as non-hazardous waste when compared to the EPA Victoria industrial waste guidelines. Regarding PAHs in FCBs modified with CBs, no studies have been conducted.

PAHs in CBs are dangerous compounds produced through the incomplete combustion and pyrolysis of tobacco. They consist of two or more aromatic rings and are hydrophobic in nature with very low water solubility. PAHs are a concern, considering that they bioaccumulate and linger in the environment, with carcinogenic, teratogenic, and mutagenic properties [23,24]. In 2008, 28 PAHs were identified as priority pollutants by the National Waste Minimization Program, a project which was funded by the US Environmental Protection Agency [25]. In a study conducted by Dobaradaran et al. [12], it was found that PAHs, particularly fluorine, acenaphthylene, naphthalene, and acenaphthene, are released into the environment from freshly littered CBs. In addition to CBs, PAH contamination in soil is a common issue, because soil is less receptive to chemical and biological degradation and the PAHs tend to absorb tightly into the organic matter present in the soil. Moreover, the recalcitrance of PAHs towards treatment increases with prolonged aging time, promoting the sequestration of PAH molecules into micropores [26].

Thus, the aim of this study was to conduct a comprehensive evaluation of PAHs in FCBs incorporated with CBs to examine the potential environmental impact of utilizing this toxic waste in the production of FCBs. In this study, a direct Soxhlet extraction method was employed using dichloromethane as the solvent. The aim of the extraction process is to effectively remove the analyte (PAHs) from its matrix, with minimal solvent usage [27]. The extract was analyzed for sixteen US EPA priority PAH compounds using gas chromatography-mass spectrometry (GC-MS) in accordance with the US EPA Method 3540C [28]. The PAH concentrations were then compared to the Environmental Protection Authority (EPA) Victorian solid industrial waste hazard categorization and management thresholds [29] to assess the suitability of FCBs incorporating CBs. Furthermore, the FCB samples incorporating CBs were studied for their carbon content using the carbon, hydrogen, nitrogen, and sulfur (CHNS) analyzer and thermogravimetric analysis (TGA).

\section{Materials and Methods}

\subsection{Materials and Brick Manufacturing Methodology}

Soil and CBs are the raw materials that were used in this study. A sieve analysis was conducted to classify the soil, and, according to unified soil classification, the soil was categorized as sandy silty clay (MC) [30]. The soil material was obtained from PGH Bricks and Pavers (Melbourne, Australia) and the CBs, of distinct brands and sizes, were provided by Butt Out Australia Pty Ltd (Melbourne, Australia). The raw materials, CBs and soil, 
were initially oven-dried at $105^{\circ} \mathrm{C}$ for $24 \mathrm{~h}$. Various percentages $(0 \%, 0.5 \%, 1 \%, 1.5 \%$, and $2 \%$ CBs by weight (wt)) of CBs were then added and uniformly mixed with the soil for $25 \mathrm{~min}$ in a mechanical mixer at a moisture content of $15.5 \%$. The fast-mixing process caused the $\mathrm{CBs}$ to shred and homogenously integrate into the soil mixture. Prior to being placed in the oven at $105{ }^{\circ} \mathrm{C}$ for $24 \mathrm{~h}$, the samples were compacted in cylindrical molds at a compaction pressure of $240 \mathrm{kPa}$. The final step involved firing the brick samples in the furnace at $1050{ }^{\circ} \mathrm{C}$ for $3 \mathrm{~h}$. For each batch, three replicate samples were prepared, tested, and the mean value was reported. The compressive strength, water absorption, initial rate of absorption, shrinkage, and density property results for the FCBs incorporating $0 \%, 0.5 \%$, $1 \%, 1.5 \%$, and $2 \%$ CBs by wt. can be found in Kurmus and Mohajerani [19].

The chemical and mineralogical composition of the CB brick samples were determined through AXS D8 Endeavor wide-angle X-ray diffractometer (XRD) (Bruker, MA, USA) and AXS S4 Pioneer spectrometer X-ray fluorescence (XRF) (Bruker, MA, USA). Powder samples were prepared by crushing and sieving the FCB samples incorporating CBs to $10 \mu \mathrm{m}$ in size. The XRD was operated at $45 \mathrm{kV}$ and $35 \mathrm{~mA}$ in reflection scanning mode from $6^{\circ}$ to $90^{\circ}$ for a total scan time of $29 \mathrm{~min}$.

\subsection{Carbon Analysis}

The CHNS-2400 Elemental Analyser (PerkinElmer, MA, USA) was used to analyze the total carbon, hydrogen, nitrogen, and sulfur content in FCBs incorporating $0 \%, 0.5 \%$, $1 \%, 1.5 \%, 2 \%$, and $5 \%$ CBs by wt. The purpose of this investigation was to determine whether carbon was trapped within the core of the brick structure from the potential incomplete combustion of CBs during the firing process. Therefore, for this experiment, only the extracted core samples were analyzed. The core of the 100-mm-diameter bricks was extracted using a 50-mm drill-saw, as shown in Figure 1. The extracted core bricks were crushed and sieved through a 1.14-mm sieve, and the quadrat sampling method was employed to select a homogeneously distributed sample for testing.

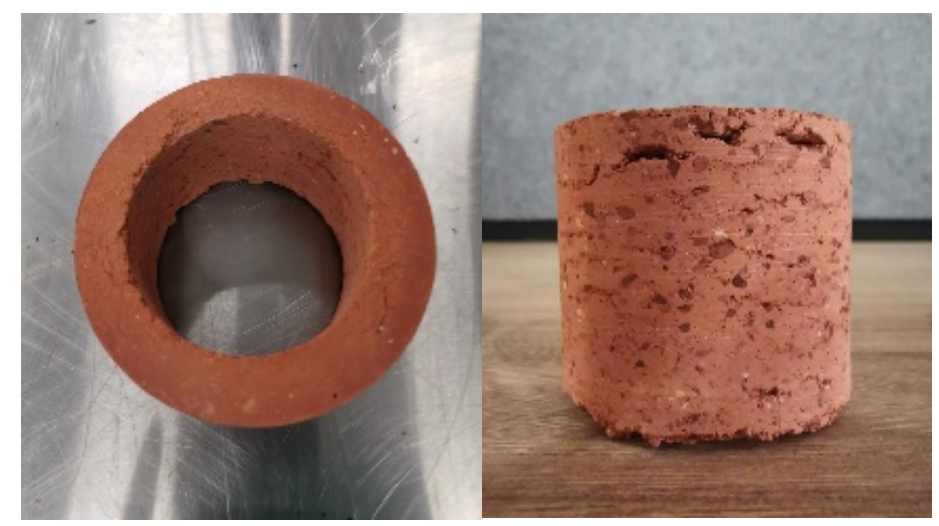

Figure 1. The core of the brick extracted for CHNS analysis.

CHNS analysis was conducted by combusting samples of $5 \mathrm{mg}$ at a high temperature of $850{ }^{\circ} \mathrm{C}$ in a chamber in the presence of oxygen. The occurrence of oxygen allows individual elements to combine with oxygen and form gaseous byproducts and water vapor such as nitrogen $\left(\mathrm{N}_{2}\right)$, sulfur dioxide $\left(\mathrm{SO}_{2}\right)$, water $\left(\mathrm{H}_{2} \mathrm{O}\right)$, and carbon dioxide $\left(\mathrm{CO}_{2}\right)$. The gases are then captured in the gas control zone and homogenized. The homogenized gases are depressurized through a column, and the separation approach is used to elute the gases, which are measured and detected by a thermal conductivity detector. In this study, three replicate samples were prepared, and the mean average was reported.

Thermogravimetric analysis (TGA) and differential thermal analysis (DTA) were performed using the TGA 8000 Autosampler (PerkinElmer, MA, USA) to monitor the mass loss of the brick samples incorporating CBs. For the thermal analysis, the samples were heated from $30^{\circ} \mathrm{C}$ to $850^{\circ} \mathrm{C}$ at a constant heating rate of $20^{\circ} \mathrm{C} / \mathrm{min}$ in a $15 \mathrm{~mL}$-per-min 
flow of nitrogen. For the purpose of this investigation, the brick samples were crushed to a particle size of $<75 \mu \mathrm{m}$. All samples were tested under the same conditions.

\subsection{Polycyclic Aromatic Hydrocarbon (PAH) Analysis}

\subsubsection{Extraction Method}

The Soxhlet extraction technique is a widely employed method to extract PAHs from sediments and soils [31]. Therefore, the brick samples were extracted in accordance with the USEPA Soxhlet Extraction Method 3540C [28]. In the basic Soxhlet extraction test, $15 \mathrm{~g}$ of crushed brick samples of particle size $<1 \mathrm{~mm}$ is placed into a cellulose thimble, which is then extracted using $300 \mathrm{~mL}$ of solvent via the reflux cycle. In this case, dichloromethane was used as the solvent. The whole assembly was heated for $8 \mathrm{~h}$ using an isomantle. The extracts from the Soxhlet extractor were concentrated to $10 \mathrm{~mL}$ using the rotary evaporator and then diluted. The concentrated samples were mixed with five isotopically labeled internal standard solutions to make a final concentration of $10 \mu \mathrm{g} / \mathrm{mL}$. The samples were stored at $4{ }^{\circ} \mathrm{C}$ for GC-MS measurement.

\subsubsection{Standards}

PAH calibration standards, including five types of isotopically labeled internal standards and 16 types of PAHs, were used for quantification. The PAH mix $(2000 \mu \mathrm{g} / \mathrm{mL})$ was purchased from Supelco and included acenaphthene, dibenz $[a, h]$ anthracene, anthracene, chrysene, benz[a]anthracene, benzo[ $b]$ fluoranthene, fluorene, benzo[ $k]$ fluoranthene, naphthalene, benzo[ $a]$ pyrene, phenanthrene, benzo[ghi]perylene, pyrene, fluoranthene, acenaphthylene, and indeno [1,2,3-cd]pyrene. The internal standards $(2000 \mu \mathrm{g} / \mathrm{mL})$ were also purchased from Supelco and included benz $[a]$ anthracene-d12 solution, chrysene-d12 solution, naphthalene-d8 solution, perylene-d12 solution, and phenanthrene-d10 solution.

Five-point standard calibration solutions were prepared to ensure the accuracy and precision of the PAHs for quantitative and qualitative analysis. The standard calibration solutions were measured at levels ranging from 1.25 to $25 \mu \mathrm{g} / \mathrm{mL}$ and internal standards of $10 \mu \mathrm{g} / \mathrm{mL}$. Each analytical series included one blank test. The 16 PAHs and five internal standards in the samples were defined by the precursor ions and retention time, as shown in Table 1.

Table 1. Physico-chemical characteristics and optimized MRM acquisition parameters of target PAHs.

\begin{tabular}{|c|c|c|c|c|c|}
\hline Compound & $\begin{array}{l}\text { Retention Time } \\
\text { (min) }\end{array}$ & $\begin{array}{l}\text { Precursor Ion } \\
(\mathrm{m} / \mathrm{z})\end{array}$ & $\begin{array}{l}\text { Product Ion } \\
\quad(\mathrm{m} / \mathrm{z})\end{array}$ & $\begin{array}{l}\text { No. of } \\
\text { Aromatic Rings }\end{array}$ & $\begin{array}{c}\text { Water } \\
\text { Solubility } \\
\text { (mg/L) }\end{array}$ \\
\hline Naphthalene & 5.51 & 128 & $128 / 128$ & 2 & 31.69 \\
\hline Naphthalene-d8 (IS) & 5.49 & 136 & $108 / 136$ & & - \\
\hline Acenaphthylene & 7.07 & 152 & $152 / 152$ & 3 & 3.93 \\
\hline Acenaphthene & 7.24 & 153 & $153 / 153$ & 3 & 3.93 \\
\hline Fluorene & 7.73 & 166 & $165 / 166$ & 3 & $1.68-1.98$ \\
\hline Anthracene & 8.66 & 178 & $178 / 178$ & 3 & 0.0446 \\
\hline Phenanthrene & 8.71 & 178 & $178 / 178$ & 3 & $1-1.6$ \\
\hline Phenanthrene-d10 (IS) & 8.64 & 188 & $160 / 188$ & & - \\
\hline Pyrene & 9.83 & 202 & $202 / 202$ & 4 & $0.129-0.165$ \\
\hline Fluoranthene & 10.05 & 202 & $202 / 202$ & 4 & 0.206 \\
\hline Chrysene & 11.22 & 228 & $228 / 228$ & 4 & $0.0015-0.0022$ \\
\hline Chrysene-d12 (IS) & 11.20 & 240 & $236 / 240$ & & - \\
\hline Benz $[a]$ anthracene & 11.26 & 228 & $228 / 228$ & 4 & 0.011 \\
\hline Benz $[a]$ anthracene-d12 (IS) & 11.23 & 240 & $236 / 240$ & & - \\
\hline Perylene-d12 (IS) & 11.75 & 241 & $241 / 242$ & & - \\
\hline Benzo[b]fluoranthene & 12.21 & 252 & $252 / 252$ & 5 & 0.0012 \\
\hline Benzo $[a]$ pyrene & 12.24 & 252 & $252 / 252$ & 5 & 0.0038 \\
\hline Benzo $[k]$ fluoranthene & 12.52 & 252 & $252 / 252$ & 5 & 0.0008 \\
\hline Benzo[ghi]perylene & 13.72 & 276 & $276 / 276$ & 6 & 0.00026 \\
\hline Dibenz $[a, h]$ anthracene & 13.74 & 278 & $278 / 278$ & 6 & 0.0005 \\
\hline Indeno $[1,2,3-c d]$ pyrene & 14.05 & 276 & $276 / 276$ & 6 & 0.062 \\
\hline
\end{tabular}




\subsubsection{GC-MS Analysis}

A GC-MS system connecting a gas chromatograph with a triple-quadrupole mass spectrometer and equipped with an auto-sampler and sample preparation robot (Agilent 7000 Series GC-MS triple quad system) was used to analyze the PAH compounds. Two Agilent DB-5MS columns $5 \mathrm{~m}$ long and $0.25 \mathrm{~mm}$ in diameter were used with mid-column backflush. The multi-mode injector was operated in solvent elimination mode with injection at $5{ }^{\circ} \mathrm{C}$, ramping at $600{ }^{\circ} \mathrm{C} / \mathrm{min}$ to $325^{\circ} \mathrm{C}$. The oven temperatures were between 5 and $325^{\circ} \mathrm{C}$ after an initial holding time of $1 \mathrm{~min}$ at $25^{\circ} \mathrm{C} / \mathrm{min}$. To attain an initial oven temperature of $5{ }^{\circ} \mathrm{C}, \mathrm{CO}_{2}$ was used as the carrier gas for cooling at a constant flow of $3 \mathrm{~mL} / \mathrm{min}$. The cryogenics mode offered the ultimate conditions for the solvent vent mode. The injection volume was set to $0.2 \mu \mathrm{L}$ and the electronic energy to $70 \mathrm{eV}$. Each run took approximately $17 \mathrm{~min}$.

\section{Results and Discussion}

\subsection{Characterization of Brick Samples}

The chemical composition of the raw clay material and bricks incorporating CBs is presented in Table 2. The data provided in Table 2 show that the major compounds in the raw clay are silicon dioxide $\left(\mathrm{SiO}_{2}\right)$, saluminum oxide $\left(\mathrm{Al}_{2} \mathrm{O}_{3}\right)$, iron(III) oxide $\left(\mathrm{Fe}_{2} \mathrm{O}_{3}\right)$, and potassium oxide $\left(\mathrm{K}_{2} \mathrm{O}\right)$. Similarly, the chemical compounds found in the FCB samples incorporating various percentages of $\mathrm{CBs}$ were $\mathrm{SiO}_{2}, \mathrm{Al}_{2} \mathrm{O}_{3}, \mathrm{Fe}_{2} \mathrm{O}_{3}$, and $\mathrm{K}_{2} \mathrm{O}$. The XRD analysis results for the raw clay soil and FCBs specimens incorporating CBs are presented in Figure 2. The XRD peak at $26.7^{\circ}$ indicates that the soil and brick samples incorporating CBs are mainly made of quartz, which is consistent with the XRF data presented in Table 2, demonstrating the presence of a large amount of silica. The second-highest peak corresponding to the raw clay soil is muscovite, a hydrated phyllosilicate mineral of aluminum and potassium, which are present in quantities of $19.95 \%$ and $2.87 \%$, respectively, in the XRF results.

Table 2. Chemical composition of raw clay soil and brick samples incorporating CBs.

\begin{tabular}{ccccccc}
\hline \multirow{2}{*}{ Component } & \multirow{2}{*}{ Raw Clay Soil (\%) } & \multicolumn{5}{c}{ Percentages of CBs by wt. } \\
\cline { 3 - 7 } & & $\mathbf{0 \%}$ & $\mathbf{0 . 5 0} \%$ & $\mathbf{1 \%}$ & $\mathbf{1 . 5 0 \%}$ & $\mathbf{2 \%}$ \\
\hline $\mathrm{Na}_{2} \mathrm{O}$ & 2.46 & 0.5 & 0.4 & 0.4 & 0.4 & 0.5 \\
$\mathrm{MgO}$ & 1.62 & 1.1 & 1.1 & 1.2 & 1.1 & 1.2 \\
$\mathrm{Al}_{2} \mathrm{O}_{3}$ & 19.95 & 16.8 & 16 & 16.5 & 16.3 & 16.8 \\
$\mathrm{SiO}_{2}$ & 62.84 & 53.8 & 52.6 & 54.8 & 53.2 & 55.3 \\
$\mathrm{P}_{2} \mathrm{O}_{5}$ & - & 0.2 & 0.2 & 0.2 & 0.3 & 0.3 \\
$\mathrm{~K}_{2} \mathrm{O}$ & 4.87 & 3.5 & 3.4 & 3.4 & 3.5 & 3.5 \\
$\mathrm{CaO}$ & 0.27 & 0.2 & 0.2 & 0.3 & 0.3 & 0.4 \\
$\mathrm{TiO}_{2}$ & 1.19 & 0.9 & 0.9 & 0.9 & 0.9 & 0.9 \\
$\mathrm{Fe}_{2} \mathrm{O}_{3}$ & 6.15 & 6.9 & 6.9 & 6.8 & 6.8 & 6.7 \\
\hline
\end{tabular}

\subsection{Carbon Analysis}

CBs contain a high content of carbon, which may stem from the unburnt tobacco, the wrapping paper, or the cellulose acetate filter, and when they are incorporated into the production of FCBs, carbon may be trapped within the brick structure. Therefore, to investigate whether the $\mathrm{CBs}$ within the brick structure completely burn off during firing, a CHNS and TG analysis was conducted. The results pertaining to organic CHNS contents and the mass loss from the TGA are shown in Table 3. As expected, FCBs incorporating 5\% CBs contain the preeminent carbon content of $0.29 \%$ due to the high CB content in the FCB, and, although it is the highest, the effect will not be significant because of the very low percentage. A carbon content less than $0.3 \%$ suggests that all carbon within the FCB-CB mixture relatively disappeared during the firing process up to $1050^{\circ} \mathrm{C}$. As displayed in Table 3, the samples contained a high content of nitrogen, which varied from $3.74 \%$ to $6.36 \%$ in the FCB samples containing between $0 \%$ and $5 \%$ CBs. This can be explained by 
the fact that nitrogen is the most abundant element in the atmosphere, and it is present in organic materials - in this case, soil-which then become available to plants, such as tobacco [32]. For the hydrogen and sulfur contents, all samples were found to contain $0 \%$.

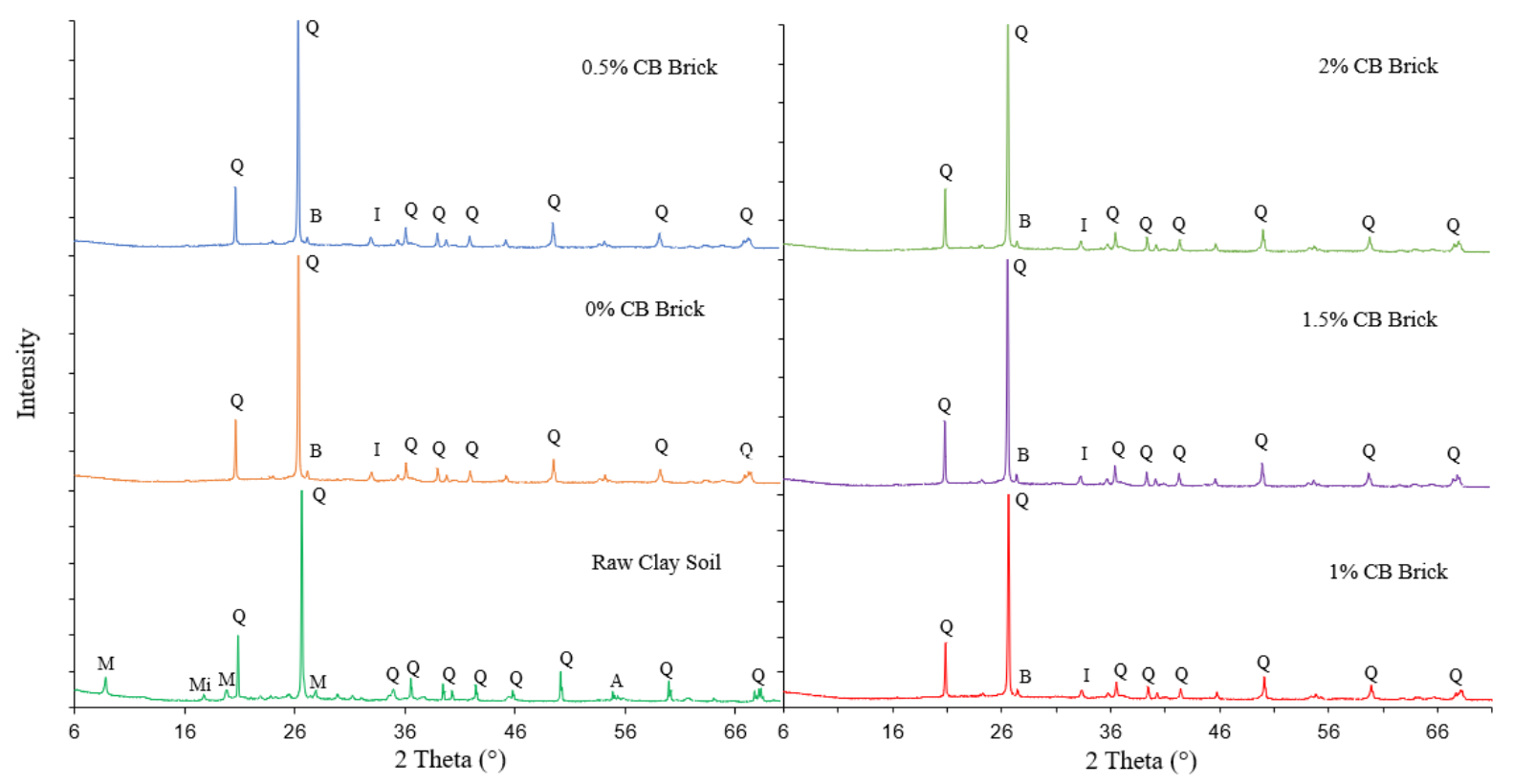

Figure 2. XRD spectra of raw clay soil and FCBs incorporating $0 \%, 0.5 \%, 1 \%, 1.5 \%$, and 2\% CBs. Q: Quartz, M: Muscovite, Mi: Mikasite, A: Albite, B: Bismuth oxide, I: Iron chromium oxide.

Table 3. Concentration of carbon, hydrogen, nitrogen, and sulfur content and mass loss in bricks incorporating $0 \%, 0.5 \%$, $1 \%, 1.5 \%, 2 \%$, and $5 \%$ CBs by wt.

\begin{tabular}{cccccc}
\hline \multirow{2}{*}{$\begin{array}{c}\text { Mixture } \\
\text { Identification (\%) }\end{array}$} & $\begin{array}{c}\text { Carbon } \\
\mathbf{( \% )}\end{array}$ & $\begin{array}{c}\text { Hydrogen } \\
\mathbf{( \% )}\end{array}$ & $\begin{array}{c}\text { Nitrogen } \\
\mathbf{( \% )}\end{array}$ & $\begin{array}{c}\text { Sulfur } \\
\mathbf{( \% )}\end{array}$ & $\begin{array}{c}\text { Mass Loss } \\
\mathbf{( \% )}\end{array}$ \\
\cline { 2 - 6 } & 0.02 & Not detected & 3.74 & Not detected & 0.41 \\
\hline CB (0) & 0.03 & Not detected & 4.74 & Not detected & 0.47 \\
\hline CB (0.5) & 0.02 & Not detected & 6.01 & Not detected & 0.54 \\
\hline CB (1.0) & 0.01 & Not detected & 6.16 & Not detected & 0.65 \\
\hline CB (1.5) & 0.04 & Not detected & 4.88 & Not detected & 0.68 \\
\hline CB (2.0) & 0.29 & Not detected & 6.36 & Not detected \\
\hline
\end{tabular}

The TGA results of the brick samples incorporating $0 \%, 0.5 \%, 1 \%, 1.5 \%$, and $2 \%$ CBs demonstrated mass losses of $0.41 \%, 0.47 \%, 0.54 \%, 0.65 \%$, and $0.68 \%$. The weight loss between 50 and $120{ }^{\circ} \mathrm{C}$ is mainly due to the removal of moisture, and the mass loss from 230 to $430{ }^{\circ} \mathrm{C}$ is primarily due to the decomposition and combustion of organic matter remaining from the incomplete combustion of the CBs or soil during the firing process at $1050{ }^{\circ} \mathrm{C}$ [33]. While the CHNS analyzer solely measures the carbon content, the mass loss from the TGA comprises both the carbon (combustion of organic matter) and moisture content, which is the source of the deviation between the results.

\subsection{Polycyclic Aromatic Hydrocarbon (PAH) Analysis}

The selected GC-MS quantification ion chromatograms of 16 PAHs in a standard mixture can be seen in Figure 3. The chromatogram displays excellent sensitivity, separation, and peak shape. The internal standards naphthalene-d8, phenanthrene-d10, perylene-d12, benz $[a]$ anthracene-d 12 , and chrysene-d12 were used to quantify naphthalene, acenaphthene, 
acenaphthylene, anthracene, fluoranthene, fluorene, phenanthrene, pyrene, benz $[a]$ anthracene, chrysene, benzo[ $[b]$ fluoranthene, benzo[ $k]$ fluoranthene, benzo[ghi]perylene, benzo[ $a]$ pyrene, dibenz $[a, h]$ anthracene, and indeno[1,2,3-cd]pyrene. The results behaved linearly over a concentration range from $1.25 \mu \mathrm{g} / \mathrm{mL}$ to $25 \mu \mathrm{g} / \mathrm{mL}$ for all 16 PAHs.

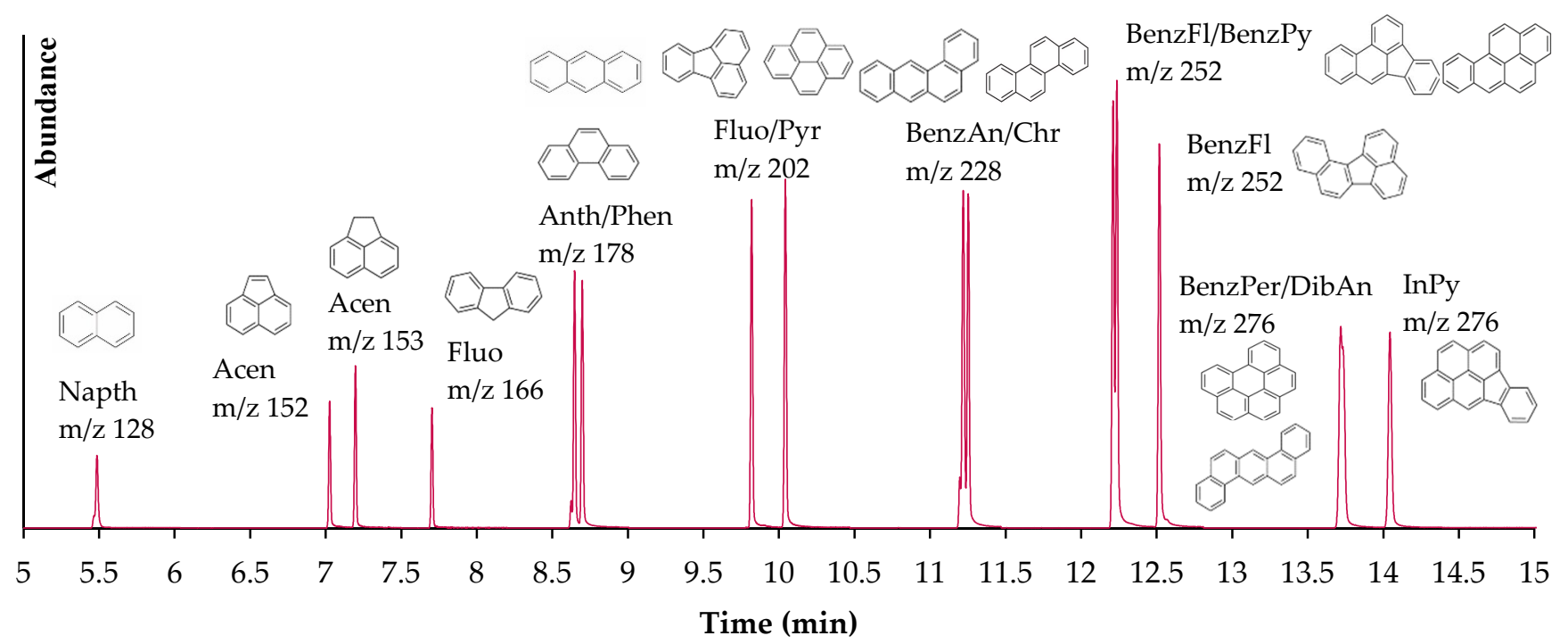

Figure 3. GC-MS chromatogram at $25 \mu \mathrm{g} / \mathrm{mL}$ in DCM for 16 PAHs.

The results of the FCBs incorporating CBs for 16 PAHs are illustrated in Figure 4. Currently, there are no similar studies involving the extraction of PAHs from FCBs or wastes recycled in FCBs to compare the results. However, research on the emission of PAHs from littered CB samples has been performed, whereby Dobaradaran et al. [12] found a mean $\Sigma \mathrm{PAH}$ concentration level of $24.6 \mu \mathrm{g} / \mathrm{mL}$ in freshly smoked CB samples and $20.4 \mu \mathrm{g} / \mathrm{mL}$ in city $\mathrm{CB}$ samples. When compared to the current study, the mean $\Sigma \mathrm{PAH}$ content in FCBs incorporating $0 \%, 0.5 \%, 1 \%, 1.5 \%$, and $2 \%$ CBs was found to be at concentrations of $0.183,0.180,0.242,0.234$, and $0.463 \mu \mathrm{g} / \mathrm{mL}$. It is apparent by incorporating CBs into the production of FCBs that a major decrease in PAH emissions into the environment is achievable. However, the major decrease in PAH concentrations may be due to several reasons, including the processes involved in manufacturing the FCB-CB samples. The brick manufacturing methods include oven drying, mixing (with water and soil), compacting, and firing, which may all result in the dissolution or evaporation of PAHs. This is further confirmed by the revised study [12], which found naphthalene to have the highest concentration level in both collected CBs from city streets and freshly smoked CB samples. In this current study, naphthalene was the second/third most prominent PAH for all sample types. The variations may be from the higher solubility of naphthalene, and thus the potential dissolution or evaporation of the PAH during the production processes, those factors being high temperatures or high-speed mixing.

Another study that involved the leachate of $\Sigma \mathrm{PAHs}$ from CBs into various water types found concentration levels ranging from 3.0 to $5.0 \mu \mathrm{g} / \mathrm{L}, 3.3$ to $5.5 \mu \mathrm{g} / \mathrm{L}$, and 3.9 to $5.7 \mu \mathrm{g} / \mathrm{L}$ for river, tap, and deionized waters, respectively [23]. The concentrations of this study are fairly low, as the study involved determining the leachate of PAHs from CBs in water samples through liquid-liquid extraction, compared to our study, which involved solid-phase extraction (SPE). The SPE method has a greater detection of sensitivity and is effective in extracting highly soluble substances. In addition to the method, the type of solvent used for extraction is critical. The initial solvent used for the Soxhlet extraction procedure was hexane-acetone (50:50). This decision was based on the theory of like dissolves like. Various studies found that dichloromethane (polar) resulted in low recoveries for all PAH (nonpolar) compounds when used as an extraction solvent, whereas hexane-acetone (nonpolar-polar) was primarily effective [34,35]. However, in our study, 
hexane-acetone resulted in chromatograms with poor sensitivity, separation, and peak shape. For this reason, the solvent was changed to dichloromethane. Dichloromethane resulted in excellent chromatograms and high PAH recoveries, as shown in Figure 3.

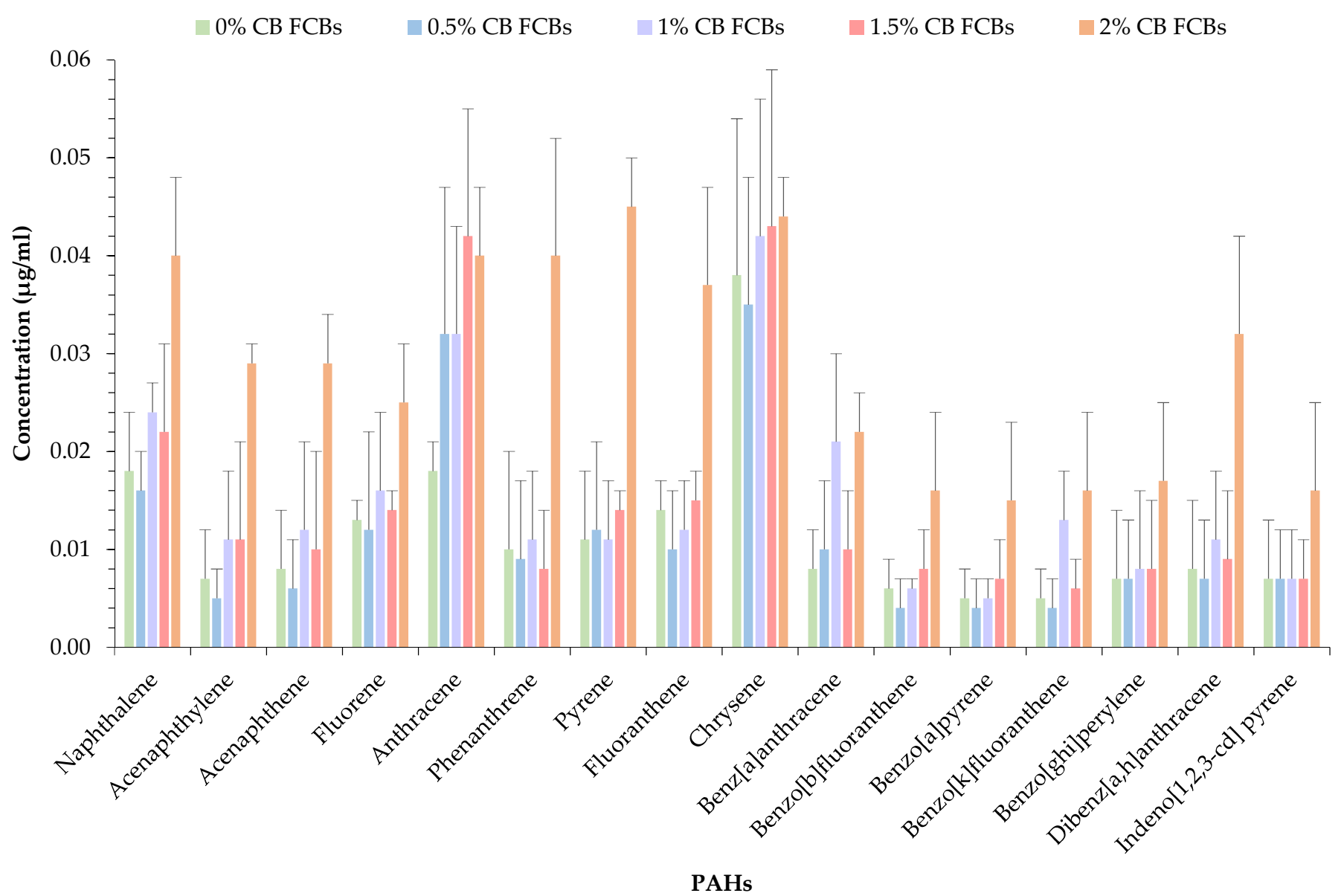

Figure 4. Results of PAHs found in FCBs incorporating $0 \%, 0.5 \%, 1 \%, 1.5 \%$, and $2 \%$ CBs.

The sample with the highest $\Sigma \mathrm{PAH}$ concentration was in the FCB samples incorporating $2 \% \mathrm{CBs}$. The order of the $\Sigma \mathrm{PAH}$ concentrations in the FCBs according to the percentage of CBs incorporated was as follows: $2 \% \mathrm{CBs}>1 \% \mathrm{CBs}>1.5 \% \mathrm{CBs}>0 \% \mathrm{CBs}>0.5 \% \mathrm{CBs}$. The sample with the highest $\mathrm{CB}$ content exhibited the highest $\Sigma \mathrm{PAH}$ content as expected, the concentration of the 16 PAHs ranging from 0.015 to $0.044 \mu \mathrm{g} / \mathrm{mL}$. However, it must be pointed out that the main raw material employed in preparing the brick samples was soil, and soil contamination is a common phenomenon. PAHs are known to absorb tightly to the organic matter in soil, rendering them less susceptible to biological and chemical degradation. For example, Saim et al. [27] extracted $1623 \mu \mathrm{g} / \mathrm{mL}$ of $\Sigma$ PAHs from coal-derived contaminated land soil using the Soxhlet extraction method, while Yu et al. [36] extracted $582 \mu \mathrm{g} / \mathrm{kg}(0.582 \mu \mathrm{g} / \mathrm{mL})$ from soils in the Guiyu area of China. Therefore, it is necessary to mention that the extracted PAH concentrations in the brick samples may be a result of the soil being contaminated, in addition to the CBs.

As shown in Figure 5, the FCB-CB samples contained a high concentration of PAHs predominately with 2-3-4-rings compared to those with 5-6-rings. Chrysene and anthracene constituted $9.5 \%$ to $20.8 \%$ and $8.6 \%$ to $17.9 \%$, respectively, of the mean $\Sigma \mathrm{PAHs}$ extracted from the brick samples. As expected, naphthalene, fluorene, anthracene, pyrene, fluoranthene, and chrysene, which are PAHs with higher water solubility and volatility, were found at higher concentrations compared to lipophilic PAHs, which include benzo[b]fluoranthene, benzo $[k]$ fluoranthene, benzo[ghi]perylene, benzo[ $a]$ pyrene, dibenz $[a, h]$ anthracene, and 
indeno[1,2,3-cd]pyrene. The lowest concentration was found at $0.004 \mu \mathrm{g} / \mathrm{mL}$ for PAHs with 5-rings. In general, the $\Sigma \mathrm{PAH}$ concentrations were the lowest in PAHs with 5-rings, followed by 6-rings, 2-rings, 3-rings, and 4-rings for all sample types.
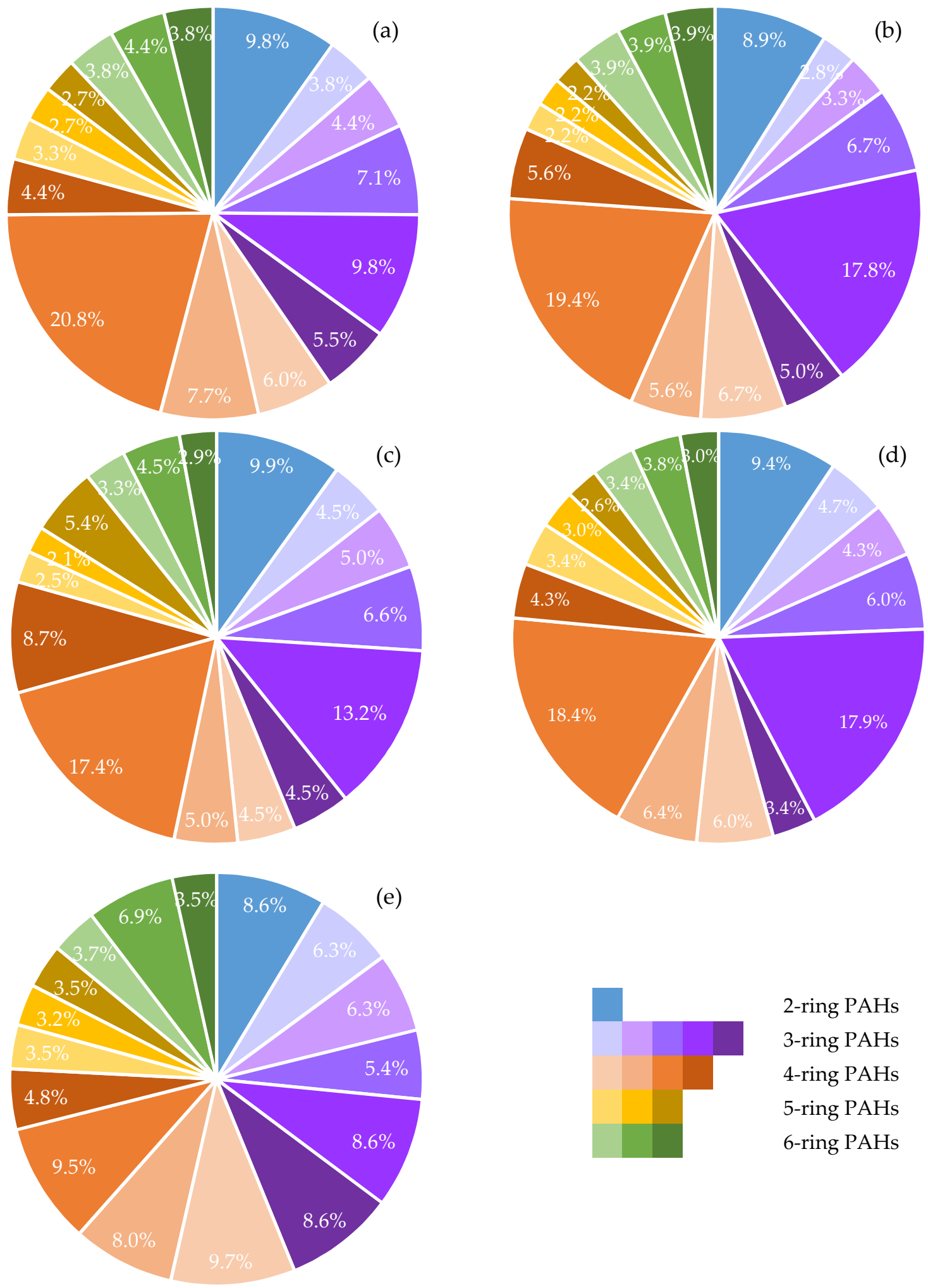

2-ring PAHs

3-ring PAHs

4-ring $\mathrm{PAHs}$

5-ring PAHs

6-ring PAHs

Figure 5. Distribution of 2-3-4-5-6-ring PAHs (\% of sum of 16 PAHs) in FCBs incorporating (a) $0 \%$, (b) $0.5 \%$, (c) $1 \%$, (d) $1.5 \%$, and (e) $2 \%$ CBs. 
According to the Industrial Waste Resource Guidelines [29], if the total PAH concentration is below $50 \mu \mathrm{g} / \mathrm{mL}$, the waste is considered industrial waste (IW). IWs are not considered prescribed wastes; therefore, they do not require control or management when disposed of to landfills and will be accepted at solid inert landfills (non-putrescible) or municipal solid waste landfills (putrescible). In this case, the mean $\Sigma$ PAHs for FCBs incorporating $0 \%, 0.5 \%, 1 \%, 1.5 \%$, and $2 \%$ CBs range between 0.180 and $0.463 \mu \mathrm{g} / \mathrm{mL}$ and are significantly below the limit of $50 \mu \mathrm{g} / \mathrm{mL}$.

\section{Conclusions}

In the present study, the concentration levels of 16 EPA-PAHs extracted from fired clay brick (FCB) samples, incorporating various percentages of cigarette butts (CBs), were evaluated. The results show that lower-molecular-weight PAHs (light PAHs), including naphthalene, fluorene, anthracene, pyrene, fluoranthene, and chrysene, with higher volatility and lower lipophilicity, were released at very low concentrations compared to the higher-molecular-weight PAHs (heavy PAHs) from FCB-CB samples.

Among the detected PAHs, chrysene and anthracene dominated the emissions and constituted $9.5 \%$ to $20.8 \%$ and $8.6 \%$ to $17.9 \%$, respectively, of the mean $\Sigma$ PAHs extracted from the brick samples. Lipophilic PAHs including benzo[b]fluoranthene, benzo[k]fluoranthene, benzo[ghi]perylene, benzo[ $a]$ pyrene, dibenz $[a, h]$ anthracene, and indeno[1,2,3-cd]pyrene demonstrated lower PAH concentrations due to their higher weights. The mean $\Sigma \mathrm{PAH}$ content in FCBs incorporating $0 \%, 0.5 \%, 1 \%, 1.5 \%$, and $2 \%$ CBs was found in concentrations of $0.183,0.180,0.242,0.234$, and $0.463 \mu \mathrm{g} / \mathrm{mL}$. As expected, the highest $\Sigma \mathrm{PAH}$ concentration was found in FCB samples incorporating $2 \% \mathrm{CBs}$. The concentrations of the mean $\Sigma \mathrm{PAH}$ for all samples were well below the EPA solid waste hazard categorization threshold limit for industrial waste.

Carbon, hydrogen, nitrogen, and sulfur (CHNS) and thermogravimetric (TG) analysis were conducted on the FCB-CB samples to investigate whether the CBs are completely combusted during the firing process. The results confirm an almost $100 \%$ combustion process during the firing process. A content less than $0.3 \%$ suggests that all carbon within the FCB-CB mixture relatively disappeared during the firing process up to $1050^{\circ} \mathrm{C}$.

It can be concluded that the results presented in this study clarify the issues raised regarding the possible release of toxic PAHs into the environment during the use and disposal of FCBs incorporating CBs or the potential storage of carbon in the FCB-CB mixture. However, further research regarding the emission of volatile organic compounds (VOCs) during the storage of $\mathrm{CBs}$ and during the mixing, oven-drying, and firing process of producing FCBs incorporating CBs should be conducted. In addition, potential deodorization and sterilization methods of CBs should be examined and implemented.

Author Contributions: Supervision: A.M.; Methodology: H.K. and A.M.; Experimental Design: H.K. and A.M.; Laboratory Investigation: H.K. and S.G.; Writing: H.K.; Editing and Reviewing: A.M. All authors have read and agreed to the published version of the manuscript.

Funding: This research received no external funding.

Institutional Review Board Statement: Not applicable.

Informed Consent Statement: Not applicable.

Data Availability Statement: Data sharing is not applicable to this article.

Acknowledgments: This work is part of an ongoing postgraduate study on recycling cigarette butts in bricks. The authors would like to thank Butt-Out Australia Pty Ltd. and RMIT University for their financial and in-kind support.

Conflicts of Interest: The authors declare no conflict of interest. 


\section{References}

1. Euromonitor International. Cigarettes, Euromonitor International. 2018. Available online: https://www.euromonitor.com/ cigarettes (accessed on 24 December 2020).

2. WHO Report on the Global Tobacco Epidemic: Monitoring Tobacco Use and Prevention Policies; World Health Organization: Geneva, Switzerland, 2017. Available online: http://apps.who.int/iris/bitstream/handle/10665/255874/9789241512824-eng.pdf; jsessionid=C8F97F8009293F9E2655830842B70178? sequence=1 (accessed on 9 December 2020).

3. Kurmus, H.; Mohajerani, A. The toxicity and valorization options of cigarette butts. Waste Manag. 2020, 104, 104-118. [CrossRef] [PubMed]

4. Clean Up Australia. Clean Up Australia Rubbish Report. 2017. Available online: https:/ /www.cleanup.org.au/rubbish-report (accessed on 1 August 2018).

5. Robertson, R.M.; Thomas, W.C.; Suthar, J.N.; Brown, D.M. Accelerated degradation of cellulose acetate cigarette filters using controlled-release acid catalysis. Green Chem. 2012, 14, 2266-2272. [CrossRef]

6. Bonanomi, G.; Incerti, G.; Cesarano, G.; Gaglione, S.A.; Lanzotti, V. Cigarette butt decomposition and associated chemical changes assessed by 13 C CPMAS NMR. PLoS ONE 2015, 10, e0117393. [CrossRef]

7. Hoffmann, D.; Hoffmann, I.; El-Bayoumy, K. The less harmful cigarette: A controversial issue. A tribute to Ernst L. Wynder. Chem. Res. Toxicol. 2001, 14, 767-790. [CrossRef]

8. Hoffmann, D.H.I. The changing cigarette, 1950-1995. J. Toxicol. Environ. Health Part A 1997, 50, 307-364. [CrossRef]

9. Micevska, T.; Warne, M.S.J.; Pablo, F.; Patra, R. Variation in, and causes of, toxicity of cigarette butts to a cladoceran and microtox. Arch. Environ. Contam. Toxicol. 2006, 50, 205-212. [CrossRef]

10. Novotny, T.E.; Lum, K.; Smith, E.; Wang, V.; Barnes, R. Cigarettes butts and the case for an environmental policy on hazardous cigarette waste. Int. J. Environ. Res. Public Health 2009, 6, 1691-1705. [CrossRef]

11. Dobaradaran, S.; Nabipour, I.; Saeedi, R.; Ostovar, A.; Khorsand, M.; Khajeahmadi, N.; Hayati, R.; Keshtkar, M. Association of metals (Cd, Fe, As, Ni, Cu, Zn and Mn) with cigarette butts in northern part of the Persian Gulf. Tob. Control 2017, 26, 461-463. [CrossRef]

12. Dobaradaran, S.; Schmidt, T.C.; Lorenzo-Parodi, N.; Jochmann, M.A.; Nabipour, I.; Raeisi, A.; Stojanović, N.; Mahmoodi, M. Cigarette butts: An overlooked source of PAHs in the environment? Environ. Pollut. 2019, 249, 932-939. [CrossRef]

13. Slaughter, E.; Gersberg, R.M.; Watanabe, K.; Rudolph, J.; Stransky, C.; Novotny, T.E. Toxicity of cigarette butts, and their chemical components, to marine and freshwater fish. Tob. Control 2011, 20, 25-29. [CrossRef]

14. Rebischung, F.; Chabot, L.; Biaudet, H.; Pandard, P. Cigarette butts: A small but hazardous waste, according to European regulation. Waste Manag. 2018, 82, 9-14. [CrossRef]

15. Mohajerani, A.; Kadir, A.A.; Larobina, L. A practical proposal for solving the world's cigarette butt problem: Recycling in fired clay bricks. Waste Manag. 2016, 52, 228-244. [CrossRef]

16. Kadir, A.A.; Mohajerani, A. Recycling cigarette butts in lightweight fired clay bricks. Constr. Mater. 2011, 164, 219-229. [CrossRef]

17. Kadir, A.A.; Mohajerani, A. Possible utilization of cigarette butts in light-weight fired clay bricks. Int. J. Civ. Environ. Eng. 2008, 2, 137-141.

18. Kadir, A.A.; Mohajerani, A.; Roddick, F.; Buckeridge, J. Density, strength, thermal conductivity and leachate characteristics of light-weight fired clay bricks incorporating cigarette butts. Proc. World Acad. Sci. Eng. Technol. 2009, 53, 1035-1040. [CrossRef]

19. Kurmus, H.; Mohajerani, A. Recycling of Cigarette Butts in Fired Clay Bricks: A New Laboratory Investigation. Materials 2020, 13, 790. [CrossRef]

20. Kurmus, H.; Mohajerani, A. Energy savings, thermal conductivity, micro and macro structural analysis of fired clay bricks incorporating cigarette butts. Constr. Build. Mater. 2021, 283, 122755. [CrossRef]

21. Mohajerani, A.; Qun Hui, S.; Shen, C.; Suntovski, J.; Rodwell, G.; Kurmus, H.; Hana, M.; Rahman, M.T. Implementation of Recycling Cigarette Butts in Lightweight Bricks and a Proposal for Ending the Littering of Cigarette Butts in Our Cities. Materials 2020, 13, 4023. [CrossRef] [PubMed]

22. Kurmus, H.; Mohajerani, A. Leachate Analysis of Heavy Metals in Cigarette Butts and Bricks Incorporated with Cigarette Butts. Materials 2020, 13, 2843. [CrossRef] [PubMed]

23. Dobaradaran, S.; Schmidt, T.C.; Lorenzo-Parodi, N.; Kaziur-Cegla, W.; Jochmann, M.A.; Nabipour, I.; Lutze, H.V.; Telgheder, U. Polycyclic aromatic hydrocarbons (PAHs) leachates from cigarette butts into water. Environ. Pollut. 2020, 259, 113916. [CrossRef] [PubMed]

24. Rochman, C.M.; Manzano, C.; Hentschel, B.T.; Simonich, S.L.M.; Hoh, E. Polystyrene plastic: A source and sink for polycyclic aromatic hydrocarbons in the marine environment. Environ. Sci. Technol. 2013, 47, 13976-13984. [CrossRef]

25. USEPA. Polycyclic Aromatic Hydrocarbons (PAHs); U.S. Environmental Protection Agency: Washington, DC, USA, 2008. Available online: https: / / archive.epa.gov / epawaste/hazard/wastemin/web/pdf/pahs.pdf (accessed on 6 September 2020).

26. Hatzinger, P.B.; Alexander, M. Biodegradation of organic compounds sequestered in organic solids or in nanopores within silica particles. Environ. Toxicol. Chem. 1997, 16, 2215-2221. [CrossRef]

27. Saim, N.; Dean, J.R.; Abdullah, M.P.; Zakaria, Z. Extraction of polycyclic aromatic hydrocarbons from contaminated soil using Soxhlet extraction, pressurised and atmospheric microwave-assisted extraction, supercritical fluid extraction and accelerated solvent extraction. J. Chromatogr. A 1997, 791, 361-366. [CrossRef] 
28. USEPA. Method 3540C: Soxhlet Extraction; USEPA: Washington, DC, USA, 1996. Available online: https://www.epa.gov/ sites/ production/files/2015-12/documents/3540c.pdf (accessed on 7 September 2020).

29. Industrial Waste Resource Guidelines. Solid Industrial Waste Hazard Categorization and Management; E.P.A.: Carlton, Australia, 2009. Available online: https://www.epa.vic.gov.au/about-epa/publications/iwrg631 (accessed on 12 April 2020).

30. Standards Australia 2009. Methods for Testing Soils for Engineering Purposes. In Soil Classification Tests-Determination of the Particle Size Distribution of a Soil—Standard Method of Analysis by Sieving (AS1289.3.6.1); SAI Global Limited: Chicago, IL, USA, 2009.

31. Lau, E.; Gan, S.; Ng, H. Extraction techniques for polycyclic aromatic hydrocarbons in soils. Int. J. Anal. Chem. 2010, 2010. [CrossRef]

32. Provin, T.; Hossner, L. What Happens to Nitrogen in Soils? 2001. Available online: https://agrilifeextension.tamu.edu/library/ gardening/what-happens-to-nitrogen-in-soils / (accessed on 12 December 2020).

33. Zhang, Y.; Jia, L.; Mei, H.; Cui, Q.; Zhang, P.; Sun, Z. Fabrication, microstructure and properties of bricks fired from lake sediment, cinder and sewage sludge. Constr. Build. Mater. 2016, 121, 154-160. [CrossRef]

34. Pena, M.; Casais, M.; Mejuto, M.; Cela, R. Optimization of the matrix solid-phase dispersion sample preparation procedure for analysis of polycyclic aromatic hydrocarbons in soils: Comparison with microwave-assisted extraction. J. Chromatogr. A 2007, 1165, 32-38. [CrossRef]

35. Shu, Y.Y.; Lai, T.L. Effect of moisture on the extraction efficiency of polycyclic aromatic hydrocarbons from soils under atmospheric pressure by focused microwave-assisted extraction. J. Chromatogr. A 2001, 927, 131-141. [CrossRef]

36. Yu, X.; Gao, Y.; Wu, S.; Zhang, H.; Cheung, K.; Wong, M.H. Distribution of polycyclic aromatic hydrocarbons in soils at Guiyu area of China, affected by recycling of electronic waste using primitive technologies. Chemosphere 2006, 65, 1500-1509. [CrossRef] 